\title{
Determination of the Mechanical Properties of Rubber by FT-NIR
}

\author{
Rattapol Pornprasit, ${ }^{1}$ Philaiwan Pornprasit, ${ }^{2}$ Pruet Boonma, ${ }^{1}$ and Juggapong Natwichai ${ }^{1}$ \\ ${ }^{1}$ Department of Computer Engineering, Faculty of Engineering, Chiang Mai University, Chiang Mai 50200, Thailand \\ ${ }^{2}$ Rubber and Polymer Technology Program, Faculty of Engineering and Agro-Industry, Maejo University, \\ Chiang Mai 50290, Thailand \\ Correspondence should be addressed to Juggapong Natwichai; juggapong@eng.cmu.ac.th
}

Received 22 November 2015; Accepted 7 February 2016

Academic Editor: Vincenza Crupi

Copyright (C) 2016 Rattapol Pornprasit et al. This is an open access article distributed under the Creative Commons Attribution License, which permits unrestricted use, distribution, and reproduction in any medium, provided the original work is properly cited.

Mechanical tests, for example, tensile and hardness tests, are usually used to evaluate the properties of rubber materials. In this work, mechanical properties of selected rubber materials, that is, natural rubber (NR), styrene butadiene rubber (SBR), nitrile butadiene rubber (NBR), and ethylene propylene diene monomer (EPDM), were evaluated using a near infrared (NIR) spectroscopy technique. Here, NR/NBR and NR/EPDM blends were first prepared. All of the samples were then scanned using a FT-NIR spectrometer and fitted with an integration sphere working in a diffused reflectance mode. The spectra were correlated with hardness and tensile properties. Partial least square (PLS) calibration models were built from the spectra datasets with preprocessing techniques, that is, smoothing and second derivative. This indicated that reasonably accurate models, that is, with a coefficient of determination $\left[R^{2}\right]$ of the validation greater than 0.9 , could be achieved for the hardness and tensile properties of rubber materials. This study demonstrated that FT-NIR analysis can be applied to determine hardness and tensile values in rubbers and rubber blends effectively.

\section{Introduction}

Polymers are one of the most important organic materials. Due to their excellent properties, polymers are applied in various fields ranging from everyday life products, for example, containers, coating, shoes, tires, rubber bands, and tubes, to industrial products, for example, construction parts and automotive materials $[1,2]$. The demand of polymers around the world was as high as 17 million tons in 2000, and this number increased to 28.7 million tons in 2014 [3]. In order to support such high demands, the production of polymers must be efficient; thus, the speed and the reliability should be considered carefully during production. Furthermore, the measuring and monitoring methods for quality control must be implemented to aid production.

Comparing natural and synthetic polyisoprene polymers, the utilization of the latter, which are obtained from fossil fuels, has been reduced due to fuel depletion. Furthermore, natural polyisoprenes have high performance properties that cannot easily be obtained with synthetic polymers. These properties include resilience, elasticity, abrasion resistance, efficient heat dispersion, and impact resistance $[4,5]$. Thus, natural polyisoprenes have been extensively used as raw materials for household, medical, and industrial products, such as gloves, tubes, and tires.

To utilize natural polyisoprenes, detailed information regarding the polyisoprene content is required for the selection of high-polyisoprene-containing lines and for determination of growth conditions. Established quantification methods of natural polyisoprenes in polyisoprene-producing plants include (i) gravimetric analysis of dried latex [6], (ii) extracted polyisoprene [7], and (iii) Fourier transform infrared spectroscopy (FT-IR) and pyrolysis-gas chromatography/mass spectrometry (PyGC/MS) analysis of extracted polyisoprene [8]. The first method is the simplest. It can be carried out with a high throughput analysis; however, the accuracy of this method is not reliable because of contamination in the latex. Meanwhile, the second and the third 
methods are much more reliable, although they require more time for the purification and extraction processes.

Near infrared (NIR) spectroscopy is a nondestructive technique which can provide detailed analysis in terms of the quantity and the quality of agricultural products [9, 10]. Specifically, NIR light can cover the region from 4,000 to $12,500 \mathrm{~cm}^{-1}$. The $\mathrm{C}-\mathrm{H}, \mathrm{O}-\mathrm{H}, \mathrm{C}-\mathrm{O}$, and $\mathrm{N}-\mathrm{H}$ bands can be observed due to stimulations of such vibrations in this spectral range [9]. The NIR spectroscopy technique has several attractive features including short analytical time, ease of operation, and having a diffused reflectance mode. Thus, NIR has been used widely in both laboratory scaled work and in industrial sectors for the qualitative and quantitative measurements of chemical components in several areas, for example, foods [11-13], agricultural products [14], materials [15], pharmaceuticals $[16,17]$, and even the oil industry [18]. Generally, multivariate calibration analysis, such as a partial least square (PLS) regression model, is built to extract information from the rather featureless NIR spectra [19]. Specifically, the model is developed from the relationship between the spectral data and their interested constituents.

For rubbers, the resin and the rubber concentration in guayule were effectively evaluated by NIR [20]. In addition, NIR has been used to study the composition of synthetic polymers and rubbers in [21-23]. Takeno et al. [8] described a Fourier transform near infrared (FT-NIR) spectroscopy technique coupled with a PLS regression model to quantify natural polyisoprene in Eucommia ulmoides leaves. It was reported that the optimal model was obtained with second derivative NIR spectra in the region between 400 and $6000 \mathrm{~cm}^{-1}\left(R^{2}\right.$, 0.95). Marinho and Monteiro [23] studied the application of NIR spectroscopy for analyzing the natural trans- and cis-polyisoprenes from Ficus elastica (cis-1,4-polyisoprene), gutta-percha (trans-1,4-polyisoprene), and mixtures of these polymers. Sirisomboon et al. [24] used FT-NIR spectroscopy in the wavelength of $1100-2500 \mathrm{~nm}$ to evaluate the dry rubber content of rubber latex. Sirisomboon et al. [25] also used short wave NIR spectroscopy in the wavelength of 700$950 \mathrm{~nm}$ to evaluate the dry rubber content and the total solids content. Their work can be applied in a concentrated latex factory.

To the best of our knowledge, applying NIR spectroscopy to evaluate the mechanical strength of vulcanized and reinforced rubber, proposed in this research, has yet to be carried out. In the process known as curing or vulcanization, sulfur is usually combined with rubber materials to accelerate crosslinkage, which increases the hardness and abrasion resistance of the rubber materials $[4,26]$. However, vulcanized rubbers may not exhibit satisfactory results in tensile strength stiffness, abrasion resistance, and tear resistance [27, 28]. These properties can be enhanced by filler constituents, such as carbon black, which act as reinforcing agents for the physical properties of rubber materials. The reinforcement by such filler usually has to be carried out before the vulcanization step. Arroyo et al. [29] reported that a reinforcing filler affects physical properties. Manufacturers usually fill polymers with carbon black particles to improve the stiffness and the toughness of the material, to enhance their resistance to fire and ignition, or simply to reduce the cost.
Polymer blends can lead to new materials, which may have better properties than each individual polymer in the blend. A polymer blend is widely accepted in industries due to the economy of scale [30]. Although a large number of combinations of polymers are available, there are a few systems which are totally miscible. Among the miscible blends, the combinations of natural rubber (NR) with ethylene propylene diene monomer (EPDM) and NR with nitrile butadiene rubber (NBR) are widely accepted and applied [31-33]. The blending between NR and EPDM can combine the excellent physical properties of NR with the ozone-resistant properties of EPDM. A principal target application of this type of blend is pneumatic tire sidewalls [34], where ozone cracking is a main factor limiting the lifetime of pneumatic tires. As a consequence, many usages which were dominated by NR, such as domestic appliances and weather seal profiles for vehicles, are almost entirely replaced by polymer blends.

In this paper, selected rubber materials, for example, natural rubber (NR) and some synthetic rubbers, such as styrene butadiene rubber (SBR), nitrile butadiene rubber (NBR), and ethylene propylene diene monomer (EPDM) are characterized. Their mechanical strength, that is, hardness and tensile, was analyzed by FT-NIR spectroscopy, and a PLS regression model was built as the calibration model. Subsequently, the performance of this model was tested using the standard error of prediction (SEP) and the root mean square error of prediction (RMSEP).

\section{Materials and Methods}

The compositions used in the present study were obtained by using roll mill equipment, according to the formulations presented in Table 1. The preparation techniques have been described elsewhere [35]. The composites were vulcanized for 20 minutes at $150 \pm 2^{\circ} \mathrm{C}$ under pressure of approximately $40 \mathrm{~kg} / \mathrm{cm}^{2}$. The reinforced materials can be obtained by mixing 50 parts filler (carbon black) to the vulcanized materials. The samples were in the form of slabs with a thickness of approximately $20.5 \mathrm{~mm}$. The rubber master batch was compounded with ingredients, for example, homogenizing agent, activators, fillers, and accelerators, using the internal mixer. The temperature of mixing was $90-120^{\circ} \mathrm{C}$. The curatives were added onto the two-roll mill to protect from scorching of the compound.

Materials. NR, SBR, NBR, and EPDM used in this study were supplied by Lucky Four Company (Nonthaburi, Thailand). All other rubber ingredients used were of commercial grade supplied by the same company. The compounding formulations are given in Table 1.

Preparation of Rubber Compound. The rubber was first mixed with a filler (carbon black: N330) in a dispersion kneader (Yong Fong Machinery Co. Ltd., Thailand) with a mixing chamber of $3 \mathrm{~L}$ at $80^{\circ} \mathrm{C}$ for 15 minutes. $\mathrm{ZnO}$, stearic acid, MBTS, and TMTD were sequentially added. The obtained mixture was then introduced to a laboratory two-roll mill (Yong Fong Machinery Co. Ltd., Thailand), and sulfur was added and mixed with the mixture on the mill for 
TABLE 1: Percentage of constituents in the reinforced sample materials.

\begin{tabular}{|c|c|c|c|c|c|c|c|c|c|c|c|}
\hline \multicolumn{2}{|l|}{ NR } & \multicolumn{2}{|l|}{ SBR } & \multicolumn{2}{|l|}{ NBR } & \multicolumn{2}{|l|}{ EPDM } & \multicolumn{2}{|c|}{$\mathrm{NR}+\mathrm{NBR}$} & \multicolumn{2}{|c|}{ NR+EPDM } \\
\hline Constituents & phr & Constituents & phr & Constituents & phr & Constituents & phr & Constituents & phr & Constituents & phr \\
\hline \multirow{2}{*}{ NR (raw) } & \multirow{2}{*}{100} & \multirow{2}{*}{ SBR (raw) } & \multirow{2}{*}{100} & \multirow{2}{*}{ NBR (raw) } & \multirow{2}{*}{100} & \multirow{2}{*}{ EPDM (raw) } & \multirow{2}{*}{100} & NR (raw) & 80 & NR (raw) & 80 \\
\hline & & & & & & & & NBR (raw) & 20 & EPDM (raw) & 20 \\
\hline $\mathrm{ZnO}$ & 5 & $\mathrm{ZnO}$ & 5 & $\mathrm{ZnO}$ & 5 & $\mathrm{ZnO}$ & 5 & $\mathrm{ZnO}$ & 5 & $\mathrm{ZnO}$ & 5 \\
\hline Stearic acid & 2 & Stearic acid & 2 & Stearic acid & 2 & Stearic acid & 2 & Stearic acid & 2 & Stearic acid & 2 \\
\hline MBTS & 1.5 & MBTS & 2 & MBTS & 1.5 & MBTS & 1.5 & Sulfur & 0.5 & Sulfur & 0.5 \\
\hline TMTD & 0.5 & TMTD & 0.5 & TMTD & 0.5 & TMTD & 0.5 & MBTS & 1.5 & MBTS & 1.5 \\
\hline Sulfur & 2.5 & Sulfur & 2.5 & Sulfur & 2.5 & Sulfur & 2.5 & TMTD & 0.5 & TMTD & 0.5 \\
\hline Carbon black & 50 & Carbon black & 50 & Carbon black & 50 & Carbon black & 50 & Carbon black & 50 & Carbon black & 50 \\
\hline
\end{tabular}

phr: part per hundred in rubber; MBTS: 2,2-dibenzothiazyl disulfide; TMTD: tetramethylthiuram disulfide; ZnO: zinc oxide.

approximately 15 minutes. The compound was then sheeted out and left at room temperature for at least 16 hours before fabricating and testing.

Cure Characteristics. The cure characteristics of the compounds were examined according to ASTM D 5289 at testing temperatures of $150^{\circ} \mathrm{C}$, using a moving die rheometer (MDR) (UR-2010, U-CAN Dynatex Inc., Taiwan). The minimum torque $\left(M_{L}\right)$, maximum torque $\left(M_{H}\right)$, torque difference $\left(M_{H}-M_{L}\right)$, scorch time, cure time, and cure rate index (CRI) were determined using NIR spectroscopy.

NIR diffuse-reflectance spectra were collected using an FT-NIR spectrophotometer (Bruker MPA) and processed with Bruker Optics' OPUS 7.0. The NIR spectra were acquired by an integrating sphere scanning an area with $1 \mathrm{~cm}$ in diameter. Sixty-four scans were averaged per scan at a spectral resolution of $16 \mathrm{~cm}^{-1}$ between 12,500 and $3,600 \mathrm{~cm}^{-1}$. The measurements were carried out at room temperature $\left(25^{\circ} \mathrm{C}\right)$ and Bruker Optics' OPUS software was used for spectral acquisition and instrumental control.

2.1. Mechanical Strength Measurements. To study the stressstrain behavior of rubber materials, an Instron universal tensile tester is used. For this purpose, the sample materials were cut from sheets in a dumb-bell shape, with tabbed ends for gripping in the test machine and tapering to a central constricted section of uniform width. The dumb-bell shape of the rubber material with the proper dimensions is shown in Figure 1. The sample material is placed in the sample holder, and its length, width, and thickness are measured. For every change of value of the load, the displacement is recorded by the computer. In a tensile testing machine, the stress is increased slowly, and the elongation of the sample at each stress level is measured; the process is repeated until the sample breaks down.

Tensile Properties. Dumbbell-shaped test samples were punched out from molded sheets. These were measured using a tensile testing machine (Model GT-AI-7000S, UTM Equipment, GOTECH) according to ASTM D412 at a crosshead speed of $500 \mathrm{~mm} / \mathrm{min}$.

Hardness is a property of considerable importance, usually included in the listed specifications of a rubber along

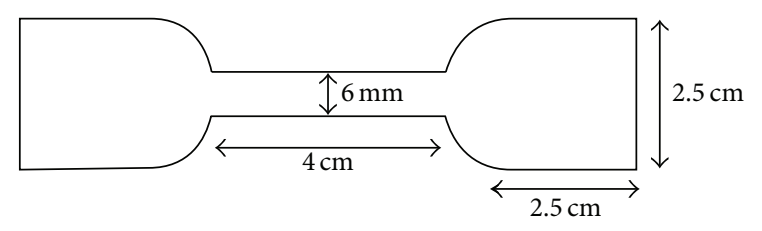

Figure 1: The dumb-bell shape of rubber samples.

with its tensile properties. The hardness values were measured with a stress of $2.65 \mathrm{~N}$ on the IRHD (International Rubber Hardness Degrees) according to ASTM D1415-88.

2.2. Data Processing. Initially, 12 datasets of the FT-NIR and reference data, that is, the hardness and tensile strength, were created for each type of polymer. As a preprocessing technique, all spectrum data were transformed via meancenter smoothing by the Savitzky-Golay method and the second derivative. Afterwards, partial least square (PLS) was applied to create a prediction model. PLS is able to find a relationship between two sets of variables, that is, the observations set and the spectrum dataset.

Partial least square (PLS) calibration models were developed in MATLAB (Math Works Inc., USA) using the routines of the PLS-Toolbox from Eigenvector (Eigenvector Research Inc., USA) to predict the hardness and the tensile strength. The optimum number of latent variables was selected on the basis of minimizing the SECV by selecting the first minimum, which was calculated with the software's internal leave-oneout method.

Calibration statistics include the root mean square error of cross-validation (RMSECV), standard error of prediction (SEP), the root mean square error of prediction (RMSEP), and the coefficient of multidetermination in cross-validation $\left(R^{2}\right)$.

\section{Results}

Our work applies Fourier transform near infrared (FT-NIR) spectroscopy to evaluate the mechanical strength of the vulcanized rubbers. The samples include NR, SBR, NBR, EPDM, and the polyblends of NR with NBR and EPDM, and 
TABLE 2: Cure characteristics of the rubber compounds.

\begin{tabular}{lcccccc}
\hline & $\begin{array}{c}M_{L} \\
(\mathrm{dNm})\end{array}$ & $\begin{array}{c}M_{H} \\
(\mathrm{dNm})\end{array}$ & $\begin{array}{c}\text { Delta torque } \\
(\mathrm{dNm})\end{array}$ & $\begin{array}{c}t_{s} \\
(\mathrm{~min})\end{array}$ & $\begin{array}{c}t_{c 90} \\
(\mathrm{~min})\end{array}$ & $\begin{array}{c}\text { CRI } \\
\left(\mathrm{min}^{-1}\right)\end{array}$ \\
\hline $\mathrm{NR}+$ & 2.64 & 21.97 & 19.33 & 1.08 & 5.36 & 22.44 \\
$\mathrm{SBR}+$ & 2.18 & 24.95 & 22.77 & 2.48 & 15.00 & 8.19 \\
$\mathrm{NBR}+$ & 1.43 & 27.97 & 26.54 & 1.04 & 5.40 & 21.73 \\
EPDM+ & 2.53 & 18.03 & 15.50 & 3.19 & 30.00 & 3.75 \\
NR+NBR+ & 3.6 & 19.14 & 15.54 & 1.43 & 7.3 & 17.3 \\
NR+EPDM+ & 2.86 & 15.42 & 12.56 & 1.55 & 10.23 & 11.81 \\
NR & 0.67 & 8.61 & 7.94 & 5.00 & 12.30 & 13.35 \\
SBR & 0.74 & 11.55 & 10.81 & 8.25 & 25.18 & 5.93 \\
NBR & 0.46 & 12.56 & 12.10 & 2.40 & 7.17 & 21.69 \\
EPDM & 0.92 & 6.90 & 5.98 & 17.24 & 41.57 & 4.07 \\
NR+NBR & 0.67 & 5.96 & 5.29 & 3.18 & 8.37 & 18.79 \\
NR+EPDM & 0.69 & 6.03 & 5.34 & 5.22 & 15.18 & 10.07 \\
\hline
\end{tabular}

all of the samples were reinforced by carbon black. Note here that the blending ratio of NR with NBR and NR with EPDM is $(70 / 30)$ as suggested by [36]. From the 600 samples, $90 \%$ were assigned as the calibration set and $10 \%$ as the validation set. The rubber materials were cured in their conditions.

Table 2 shows the cure characteristics of the compounds containing different rubber types with unfilled and filled carbon black. The scorch time $\left(t_{s}\right)$ generally defines the onset set of vulcanization at a particular temperature and thus represents the time limit available for processing. Cure time $\left(t_{c 90}\right)$ is the time required during the vulcanization step for a required amount of cross-linking to occur, yielding the desired properties. Minimum torque $\left(M_{L}\right)$ is related with the viscosity or plasticity of the unvulcanized stock, while maximum torque $\left(M_{H}\right)$ and torque difference (Delta torque) may give an idea of the maximum extent of curing (i.e., the cross-link density).

The incorporation of carbon black increased the viscosity of rubber. Scorch time and cure time are also shorter when carbon black loading is employed. The carbon black generates heat buildup in the compounds under shear conditions in the kneader. When the filler is used, heat is also generated in the system because the compound tends to be more viscous. As a consequence, vulcanization reactions can occur more readily so that the viscosity increases while the scorch time and the cure time are shortened.

The minimum and maximum torques, $M_{L}$ and $M_{H}$, and the Delta torque increase with increasing carbon black content. The increase in Delta torque is in line with the wellknown behavior of a viscosity increase with the addition of carbon black. Delta torque is generally related to the degree of cross-linking, and hence its increase can be attributed to the increase of the cross-link density. The decrease in the scorch time is due to the restriction of the mobility and the deformability of the matrix with the introduction of mechanical restraints. The increase of the cure rate index results from the basicity of carbon black, which accelerates the vulcanization reaction. The effects of carbon black loading on rheological properties are shown in Table 3.
TABLE 3: The values of the mechanical strength in rubber compound samples.

\begin{tabular}{lccc}
\hline Sample & Reinforced & Hardness & Tensile (MPa) \\
\hline NR & + & 77.15 & 17.59 \\
SBR & + & 75.36 & 15.4 \\
NBR & + & 79.74 & 15.29 \\
EPDM & + & 64.86 & 10.79 \\
NR+NBR & + & 70.22 & 21.19 \\
NR+EPDM & + & 70.4 & 20.99 \\
NR & - & 43.24 & 3.04 \\
SBR & - & 48.15 & 1.53 \\
NBR & - & 51.75 & 2.02 \\
EPDM & - & 32.7 & 0.58 \\
NR+NBR & - & 35.29 & 15.95 \\
NR+EPDM & - & 35.11 & 13.21 \\
\hline
\end{tabular}

From Chough and Chang [37], the number of allylic hydrogen atoms influences the cure rate of a rubber compound. A higher allylic hydrogen content uses a lower overall apparent activation energy of curing, thereby increasing the speed of the cure rate. Therefore, longer scorch and cure times are attributed to lower allylic hydrogen contents of the blended rubber compounds. Generally, statistical repeated units of NR and SBR have 7 and 3.3 allylic hydrogen atoms, respectively [37].

The mechanical properties of polymer-based materials, such as the deformation of the sample in terms of tension and the depth of penetration, determine their potential applications through tensile and hardness tests. Table 3 shows the results of the average of the mechanical strength of each sample. This table shows that the carbon black affected the mechanical strength in all sample types. In addition, polyblend samples show higher mechanical strengths than those of unfilled vulcanized rubbers. This finding might be attributed to good rubber-filler interactions. While the uncured rubber blended well with carbon black for a period of time, rubber chains have a certain probability to be in contact with carbon black, causing the chains to be entangled or trapped in the voids of carbon black aggregates. The surfaces of carbon black particles were covered by entangled rubber chains and can be considered as physical cross-links. The physical cross-linking hinders the mobility of rubber chains and restrains the deformation of rubber; thus, $M_{L}$ of filled rubber enhances even though it is in the uncured state. The entanglement of polymer chains with carbon black increases the torque; thereby, carbon black serves as physical cross-links in rubbers. $M_{L}$, the torque of melting uncured rubbers at $150^{\circ} \mathrm{C}$, is an indicator of the degree of physical cross-linking.

The hardness of vulcanized rubber materials is between 32 and 51 in which NBR shows the highest hardness due to the acrylonitrile component in its molecular structure, while the tensile strength is between 0.5 and $15 \mathrm{MPa}$, with the polyblend of NR/NBR showing the highest tensile property. In general, reinforced rubber materials show higher mechanical strengths than unfilled vulcanized rubbers. 


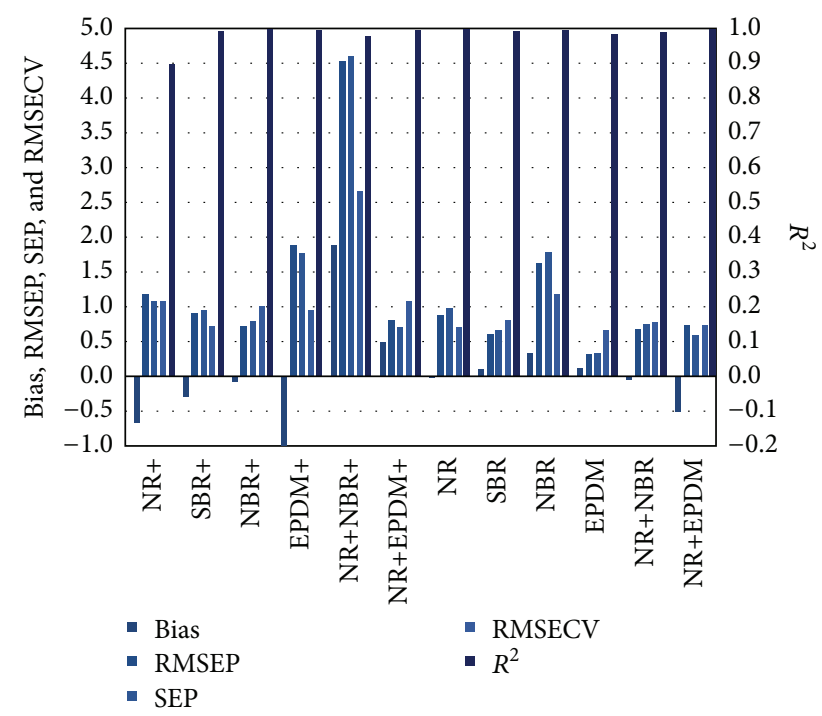

FIGURE 2: The calibration performance of the PLS regression for hardness.

Hardness is one of the most widely measured properties in rubber materials, as it is a practical way of determining the degree of vulcanization. The hardness represents the elasticity of the material. In Figure 2, the results showed the performance of the PLS model for each dataset from their prediction model. Overall, the models are very good, achieving high $R^{2}$ s between 0.88 and 0.99 and also bias well. From this figure, the dataset of the polyblend of NR with NBR shows high RMSECV, SEP, and RMSEP values with good $R^{2}$.

The tensile strength is the maximum tensile stress reached in stretching a test piece to its breaking point. Hence, this value is used to correlate with the NIR spectrum. The calibration models were built by the spectrum data and were used to predict the tensile strength. Figure 3 shows the results of the performance of the prediction model, indicating good bias with $R^{2}$ values from 0.8 to 0.9 . Although the RMSEP and SEP values of the predicted tensile model are higher than those of the predicted hardness model, the values are in the acceptable range.

The various rubber materials used in this study are NR, NBR, SBR, EPDM, and polyblends of NR with NBR and EPDM, in the raw state and in the reinforced state. From the mechanical strength measurements shown in Table 3, the reinforced rubbers have higher hardness values than the raw rubbers with the highest hardness observed in reinforced NBR, NR, and NBR at 79, 77, and 75, respectively. The polyblends of NR with NBR and EPDM show hardness of 35. The results of the tensile strength are the same as the hardness results, in that reinforced rubbers exhibited higher tensile strengths than raw rubbers. The highest tensile strengths are found in reinforced polyblends of NR/NBR and NR/EPDM at 21 and $20 \mathrm{MPa}$, respectively.

FT-NIR is used to evaluate the mechanical strengths of raw and reinforced rubber elastomers, for example, NR, SBR, NBR, EPDM, and polyblends of NR with NBR and EPDM. From Figures 2 and 3, good performance was observed in the prediction models created by PLS regression. The

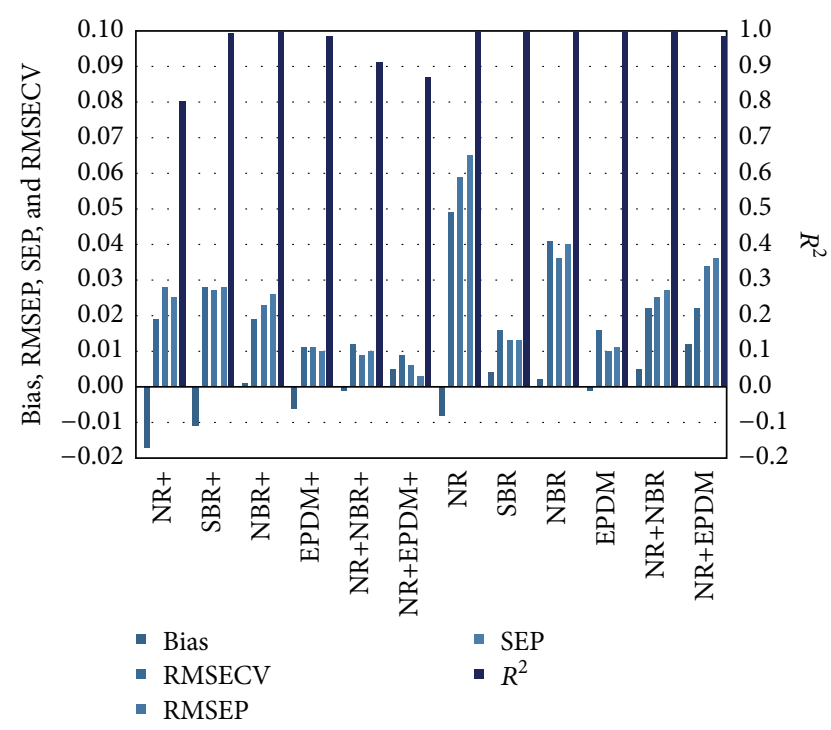

FIGURE 3: The calibration performance of the PLS regression for the tensile strength.

models were built by correlating the whole NIR spectra with the mechanical strengths. Hence, FT-NIR spectroscopy was efficient in estimating the hardness and tensile strength of vulcanized rubbers, and this approach was successfully applied to raw, reinforced, and blended rubber materials.

\section{Conclusion}

This study shows that FT-NIR is a potential method for evaluating the mechanical strength of compound rubber. The PLS regression model was developed from the dataset and indicates an acceptable prediction performance for the hardness and tensile strength of rubber materials. However, the calibration models from FT-NIR and the mechanical strength are limited to specific components of the rubber materials. Although it is not difficult to operate the calibration software, extensive training and experience and accurate chemical analysis of the calibration samples are required to develop a comprehensive and accurate analytical equation for each constituent. Further research efforts will focus on variable selection and other mathematic models as calibration models.

\section{Conflict of Interests}

The authors declare that there is no conflict of interests regarding the publication of this paper.

\section{Acknowledgment}

This work was supported by the 2014 Post-Doctoral Fellowship Program of Chiang Mai University.

\section{References}

[1] J. S. Dick, Compounding Materials for the Polymer Industries, Noyes, Park Ridge, Ill, USA, 1987. 
[2] S. Chuayjuljit, A. Imvittaya, N. Na-Ranong, and P. Potiyaraj, "Effects of particle size and amount of carbon black and calcium carbonate on curing characteristics and dynamic mechanical properties of natural rubber," Journal of Metals, Materials and Minerals, vol. 12, no. 1, pp. 51-57, 2002.

[3] Departmentof Statistics Malaysia, "Natural Rubber statistics 2015," Report, Malaysia Rubber Board, Kuala Lumpur, Malaysia, 2015, http://www.lgm.gov.my/nrstat/nrstats.pdf.

[4] M. Morton, Rubber Technology, Springer Science \& Business Media, Boston, Mass, USA, 2013.

[5] H. Ismail, Z. Ahmad, and Z. A. Mohd Ishak, "Comparison of cetyltrimethylammonium maleate and sulphenamide as an accelerator in carbon black filled natural rubber compounds," Polymer Testing, vol. 20, no. 6, pp. 607-614, 2001.

[6] P. Suwanmanee, N. Sirinupong, and W. Suvachittanont, "Regulation of the expression of 3-hydroxy-3-methylglutaryl-CoA synthase gene in Hevea brasiliensis (B.H.K.) Mull. Arg," Plant Science, vol. 166, no. 2, pp. 531-537, 2004.

[7] K. Cornish, M. H. Chapman, F. S. Nakayama, S. H. Vinyard, and L. C. Whitehand, "Latex quantification in guayule shrub and homogenate," Industrial Crops and Products, vol. 10, no. 2, pp. 121-136, 1999.

[8] S. Takeno, T. Bamba, Y. Nakazawa, E. Fukusaki, A. Okazawa, and A. Kobayashi, "Quantification of trans-1,4-polyisoprene in Eucommia ulmoides by fourier transform infrared spectroscopy and pyrolysis-gas chromatography/mass spectrometry," Journal of Bioscience and Bioengineering, vol. 105, no. 4, pp. 355-359, 2008.

[9] P. Williams and K. Norris, Near-Infrared Technology in the Agricultural and Food Industries, American Association of Cereal Chemists, Eagan, Minn, USA, 2nd edition, 2001.

[10] P. Williams and K. Norris, Near-Infrared Technology in the Agricultural and Food Industries, American Association of Cereal Chemists, 1987.

[11] L. Nørgaard, M. T. Hahn, L. B. Knudsen, I. A. Farhat, and S. B. Engelsen, "Multivariate near-infrared and Raman spectroscopic quantifications of the crystallinity of lactose in whey permeate powder," International Dairy Journal, vol. 15, no. 12, pp. 12611270, 2005.

[12] H. Cen, Y. Bao, Y. He, and D.-W. Sun, "Visible and near infrared spectroscopy for rapid detection of citric and tartaric acids in orange juice," Journal of Food Engineering, vol. 82, no. 2, pp. 253260, 2007.

[13] T. Ikeda, S. Kanaya, T. Yonetani, A. Kobayashi, and E. Fukusaki, "Prediction of Japanese green tea ranking by fourier transform near-infrared reflectance spectroscopy," Journal of Agricultural and Food Chemistry, vol. 55, no. 24, pp. 9908-9912, 2007.

[14] V. A. McGlone and S. Kawano, "Firmness, dry-matter and soluble-solids assessment of postharvest kiwifruit by NIR spectroscopy," Postharvest Biology and Technology, vol. 13, no. 2, pp. 131-141, 1998.

[15] P. J. Corish, "Analysis of cis- and trans-1:4 contents of polyisoprenes by near infra-red spectroscopy," Spectrochimica Acta, vol. 15, pp. 598-604, 1959.

[16] C. Bodson, W. Dewé, P. Hubert, and L. Delattre, "Comparison of FT-NIR transmission and UV-vis spectrophotometry to follow the mixing kinetics and to assay low-dose tablets containing riboflavin," Journal of Pharmaceutical and Biomedical Analysis, vol. 41, no. 3, pp. 783-790, 2006.
[17] M. J. Barajas, A. R. Cassiani, W. Vargas et al., "Near-infrared spectroscopic method for real-time monitoring of pharmaceutical powders during voiding," Applied Spectroscopy, vol. 61, no. 5, pp. 490-496, 2007.

[18] M. Blanco, S. Maspoch, I. Villarroya, X. Peralta, J. M. González, and J. Torres, "Determination of physico-chemical parameters for bitumens using near infrared spectroscopy," Analytica Chimica Acta, vol. 434, no. 1, pp. 133-141, 2001.

[19] M. P. Fuller, G. L. Ritter, and C. S. Draper, "Partial least-squares quantitative analysis of infrared spectroscopic data. Part II. Application to detergent analysis," Applied Spectroscopy, vol. 42, no. 2, pp. 228-236, 1988.

[20] L. T. Black, G. E. Hamerstrand, and W. F. Kwolek, "Analysis of rubber, resin, and moisture content of guayule by near infrared reflectance spectroscopy," Rubber Chemistry and Technology, vol. 58, no. 2, pp. 304-313, 1985.

[21] J. Guilment and L. Bokobza, "Determination of polybutadiene microstructures and styrene-butadiene copolymers composition by vibrational techniques combined with chemometric treatment," Vibrational Spectroscopy, vol. 26, no. 1, pp. 133-149, 2001.

[22] L. Kleine and M. Foster, "Chemometric NIR calibration for guayule analysis," in Proceedings of the 1st International Conference on New Industrial Crops and Products, pp. 8-10, Riverside, Calif, USA, 1990.

[23] J. R. D. Marinho and E. E. C. Monteiro, "Analysis of natural cisand trans-polyisoprene mixtures by near-infrared spectrophotometry," Polymer Testing, vol. 19, no. 6, pp. 667-672, 2000.

[24] P. Sirisomboon, A. Kaewkuptong, and P. Williams, "Feasibility study on the evaluation of the dry rubber content of field and concentrated latex of Para rubber by diffuse reflectance near infrared spectroscopy," Journal of Near Infrared Spectroscopy, vol. 21, no. 2, pp. 149-156, 2013.

[25] P. Sirisomboon, M. Deeprommit, W. Suchaiboonsiri, and W. Lertsri, "Shortwave near infrared spectroscopy for determination of dry rubber content and total solids content of Para rubber (Hevea brasiliensis) latex," Journal of Near Infrared Spectroscopy, vol. 21, no. 4, pp. 269-279, 2013.

[26] A. K. Bhowmick, Rubber Products Manufacturing Technology, CRC Press, New York, NY, USA, 1994.

[27] A. R. Payne, “The dynamic properties of carbon black-loaded natural rubber vulcanizates. Part I," Journal of Applied Polymer Science, vol. 6, pp. 57-63, 1962.

[28] O. H. Yeoh, "Characterization of elastic properties of carbonblack-filled rubber vulcanizates," Rubber Chemistry and Technology, vol. 63, no. 5, pp. 792-805, 1990.

[29] M. Arroyo, M. A. López-Manchado, and B. Herrero, "Organomontmorillonite as substitute of carbon black in natural rubber compounds," Polymer, vol. 44, no. 8, pp. 2447-2453, 2003.

[30] D. R. Paul, Polymer Blends, vol. 1, Elsevier, 2012.

[31] M. H. Walters and D. N. Keyte, "Heterogeneous structure in blends of rubber polymers," Rubber Chemistry and Technology, vol. 38, no. 1, pp. 62-75, 1965.

[32] M. Xanthos and S. Dagli, "Compatibilization of polymer blends by reactive processing," Polymer Engineering \& Science, vol. 31, pp. 929-935, 1991.

[33] L. Yu, K. Dean, and L. Li, "Polymer blends and composites from renewable resources," Progress in Polymer Science, vol. 31, no. 6, pp. 576-602, 2006.

[34] A. Tinker and K. Jones, UNCFC-In Blends of Natural Rubber, United Nations Common Fund for Commodities, 1998. 
[35] S. E. Gwaily, G. M. Nasr, M. M. Badawy, and H. H. Hassan, "Thermal properties of ceramic-loaded conductive butyl rubber composites," Polymer Degradation and Stability, vol. 47, no. 3, pp. 391-395, 1995.

[36] J. Clarke, B. Clarke, P. K. Freakley, and I. Sutherland, "Compatibilising effect of carbon black on morphology of NRNBR blends," Plastics, Rubber and Composites Processing and Applications, vol. 30, no. 1, pp. 39-44, 2001.

[37] S.-H. Chough and D.-H. Chang, "Kinetics of sulfur vulcanization of NR, BR, SBR, and their blends using a rheometer and DSC," Journal of Applied Polymer Science, vol. 61, no. 3, pp. 449454, 1996. 

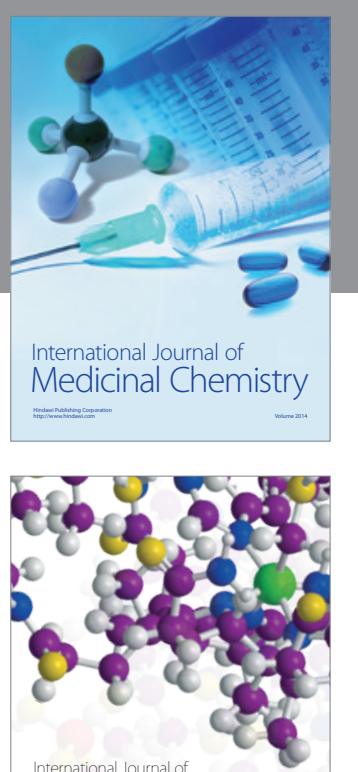

Carbohydrate Chemistry

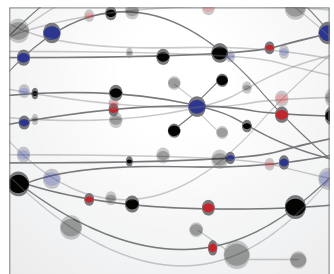

The Scientific World Journal
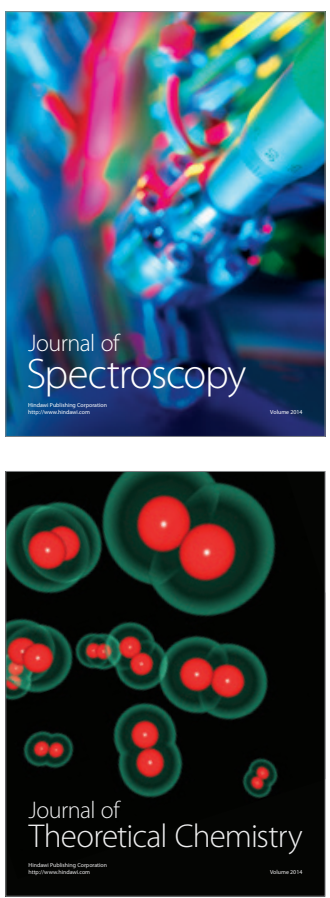
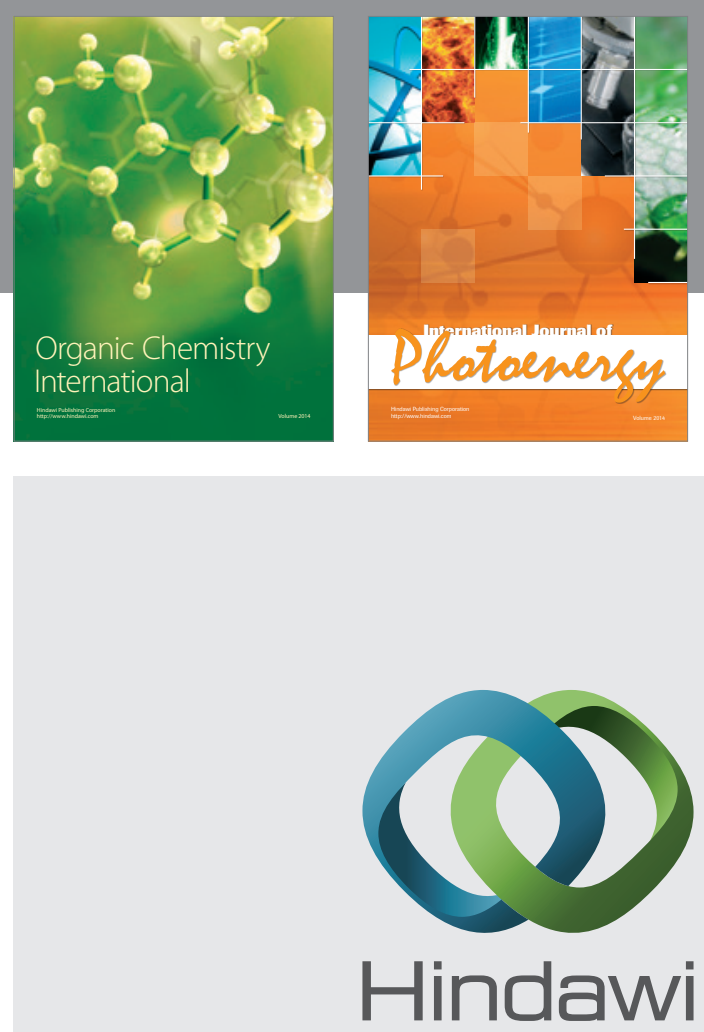

Submit your manuscripts at

http://www.hindawi.com

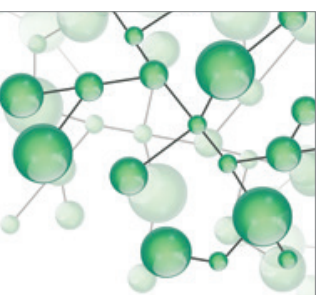

International Journal of

Inorganic Chemistry

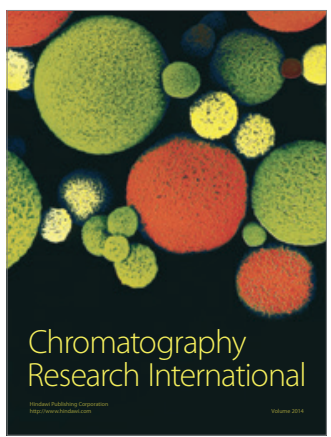

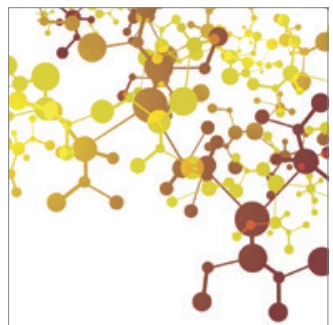

Applied Chemistry
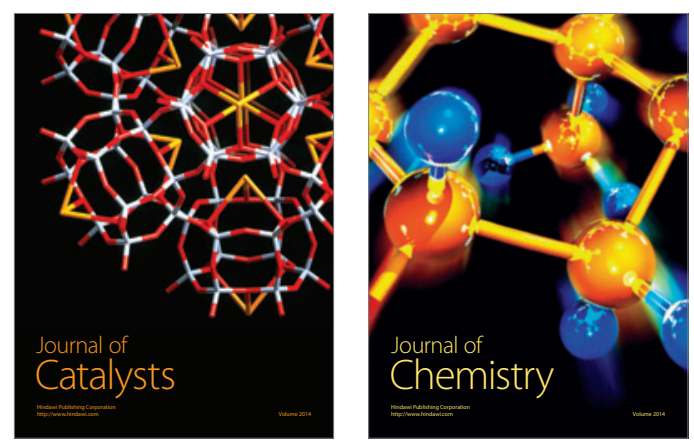
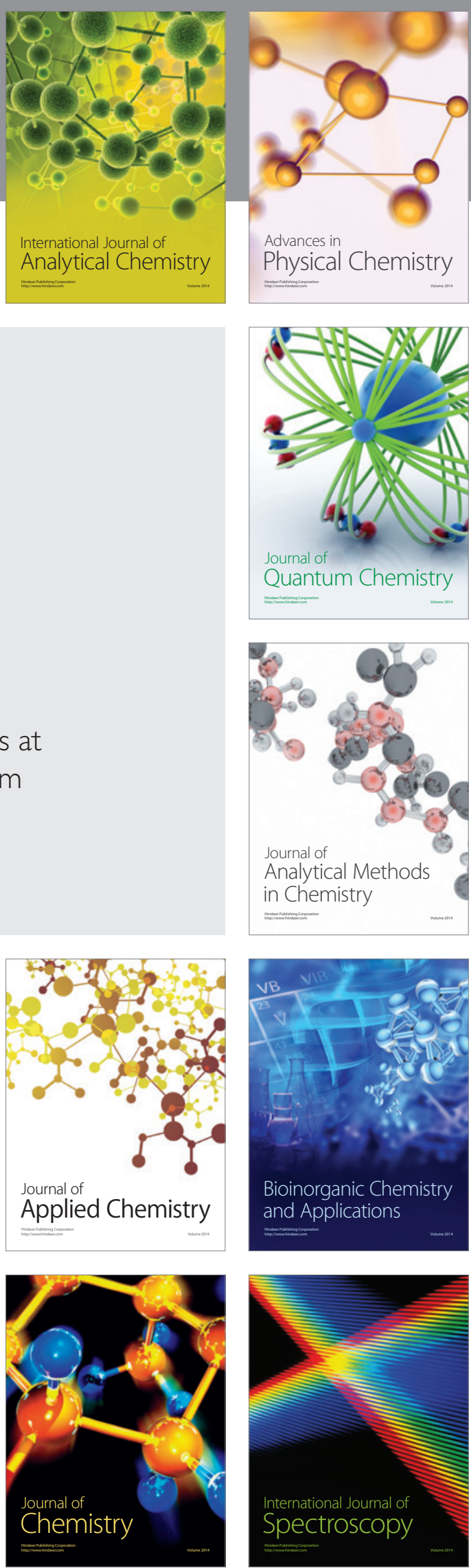